IP Periodica Polytechnica

Mechanical Engineering

59(2), pp. 94-101, 2015

DOI: 10.3311/PPme.7936

Creative Commons Attribution (i)

RESEARCH ARTICLE

\section{A Simplified Modeling Approach for Rolling Piston Compressors}

\author{
Balázs Farkas $^{1 *}$, Viktor Szente $^{1}$, Jenő Miklós Suda ${ }^{1}$
}

Received 26 January 2015; accepted after revision 12 March 2015

\begin{abstract}
A new type of thermodynamic machine was designed and prepared for testing to evaluate its capability in extracting mechanical energy from low enthalpy heat sources. The system was completed with a newly designed rotary piston compressor and expander to improve efficiency. A numerical model was set up using commercially available CFD code ANSYS Fluent to evaluate the performance of the compressor and to identify the fluid dynamic related loss sources. In attempt to increase computational efficiency $3 D$ and $2 D$ computations were compared to find the simplest model which provides sufficient information to capture the important heat transfer and fluid mechanical features.
\end{abstract}

\section{Keywords}

Rotary compressor, Rolling piston compressor, CFD, Porous resistance model

\section{Introduction}

A new high efficiency compressor design was introduced as a part of a project where the aim was to find a new way to extract mechanical energy from low enthalpy geothermal resources.

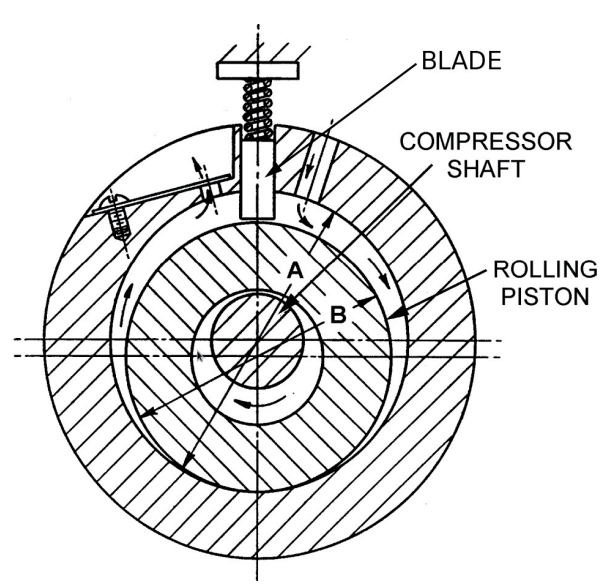

(a)

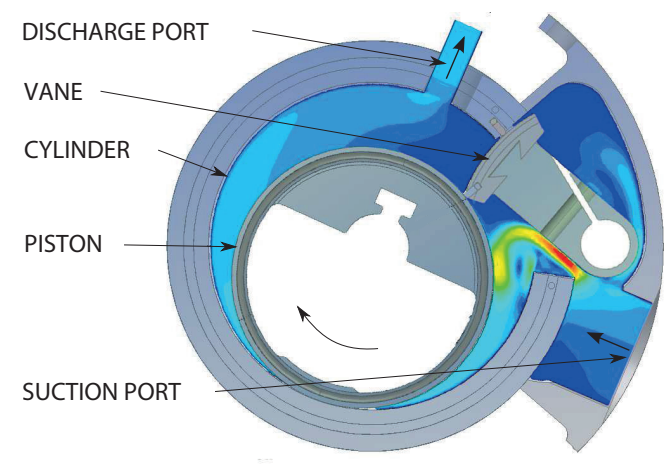

(b)

Fig. 1 Traditional fixed vane rolling piston compressor [1] (a) compared to the modified design (b)

The new design is based on the architecture of the classic rolling piston type compressors (Fig. 1(a)) which are widely used in air-conditioning and cooling systems because of the high volumetric efficiency due to the small clearance volume and correspondingly low re-expansion losses inherent in their
${ }^{1}$ Department of Fluid Mechanics, Faculty of Mechanical Engineering, Budapest University of Technology and Economics,

H-1111 Budapest, Bertalan Lajos u. 4-6., Hungary

*Corresponding author, e-mail: farkas@ara.bme.hu 
design [1]. To improve the performance, the original design was slightly modified [2] and unlike in the case of conventional rolling piston compressors here the piston does not roll along the surface of the cylinder but instead the piston is solidly mounted on the drive shaft (Fig. 1(b)). This design makes it similar to the trochoidal compressors which do not require extremely small and expensive manufacturing tolerances because of the closed sealing border of the compression space and neither do they need oil for sealing [1]. The spring loaded blade which separates the suction and the pressure side is also replaced by a vane which is driven directly by the drive shaft to keep the sealing clearance constant without increasing the friction losses induced by the traditional spring loaded blade.

Apart from these differences in design the compression process is similar to the traditional rolling piston compressors az shown in Figs. 2 and 3 where $\left(n^{*}=0.102\right) .0^{\circ}$ crank angle is defined where the center of the rotation and the center of gravity of the piston is aligned with the contact point of the vane. The suction process starts when the piston passes over the suction orifice. During the suction part of the cycle, gas is drawn through a suction port into the suction chamber as its volume is increased. Simultaneously, the compression and discharge processes take place in the decreasing volume for the other chamber, on the opposite side of the piston and vane. The gas is compressed until the pressure in the compression chamber becomes higher than the pressure in the discharge line. Then the discharge process takes place until the piston passes over the discharge orifice [3].

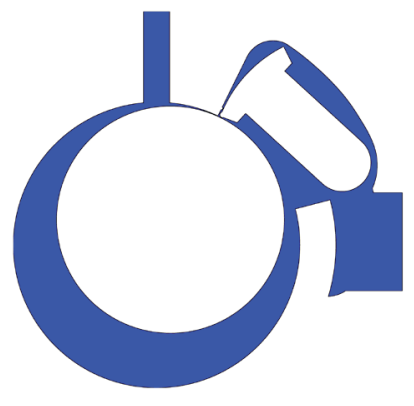

(a) $0^{\circ}$

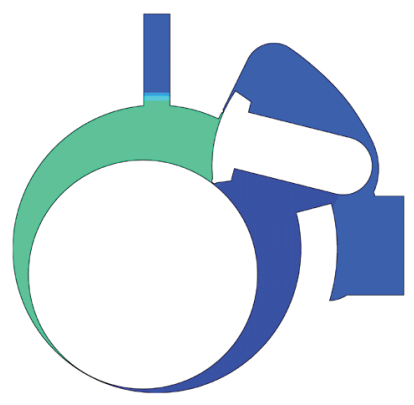

(c) $180^{\circ}$

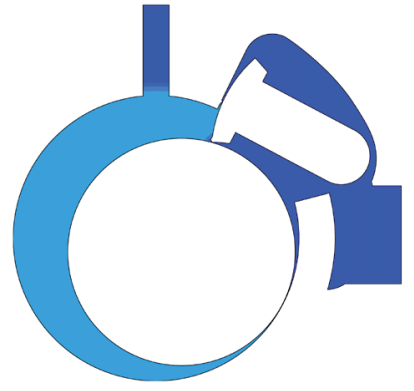

(b) $90^{\circ}$

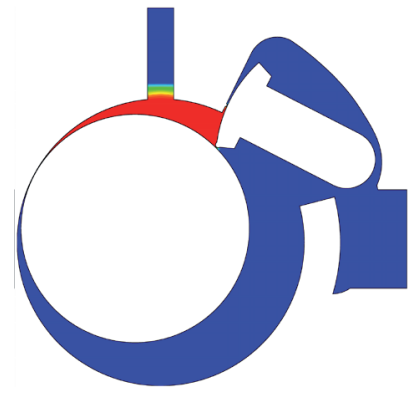

(d) $270^{\circ}$
Fig. 2 Pressure distribution within the cylinder at different crankshaft positions

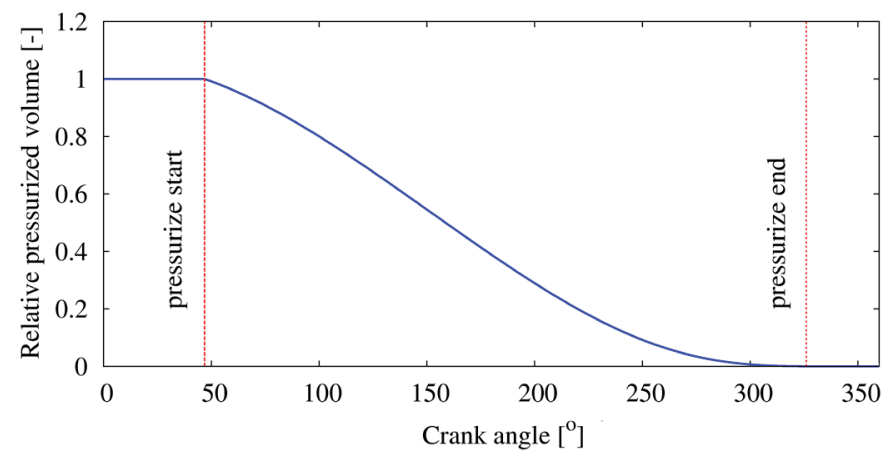

Fig. 3 Relative volume of the pressurized volume in function of the crankshaft position

It is known that the actual P-V diagram differs from the ideal thermodynamic cycle and the deviation of each of the thermodynamic processes of suction, compression, discharge and expansion from the ideal are attributable to fluid dynamic causes. For example the most important process of compression is affected by leakage, unsteady heat transfer across the boundaries of the compression volume and some viscous shear at the boundaries. To identify and quantify these phenomena Computational Fluid Dynamics (CFD) is known to be a very economical tool during evolutionary design process [4]. Therefore CFD tools were used extensively in former studies modeling rotary compressors. Chun Hui et. [5] used CFD models in their study to compare the performance of a two cylinder rolling piston type compressor equipped with two different, separate and common suction piping systems. The results were compared to experimental data and confirmed that the common suction pipe solution noticeably reduces the noise level by attenuating the pressure pulsations. Shebing Liang et al. [6] modeled a similar system designed for household air conditioners to gain the internal flow characteristics to optimize their design process. The results were also confirmed by measurements and the difference from the CFD estimated data was below $10 \%$ in case of cooling capacity predictions meanwhile the resemblance in case of pressure characteristics was particular. Although the influence of the lubricating oil and the leakage flow was not considered. Simplified porous media approach was used to model tip leakage flow in the 3D CFD model for a rotary vaned expander presented by Gianluca et al. [7]. The model allowed to estimate the effect of the leakage flow on volumetric efficiency. The gained results claimed to show encouraging agreement with the experimental data and justified the suitability of the applied real gas approach emphasizing that the resistance coefficient used for modeling of the leakage flow has to be calibrated. Also remark was made that despite the agreeable results the applied mesh resolution should have been at least one order of magnitude finer than the one was used but which would have significantly increased the computational cost. Promising results was shown by Hui Ding et al. [8] in a more recent study where the aim was to assess the 
capability of a purpose specific CFD software in simulating the flow within a rolling piston compressor equipped with a reed valve. Although experimental data here were not available the program appeared to be fast and robust, capable of simulating a whole revolution of the piston within hours with using moderate computational power.

By the nature of their working process the cavities within the volumetric compressors are subjected to complex deformations. Therefore deforming mesh has to be used to simulate transient effects. That makes the simulation of essential phenomena such as leakage flows and heat transfer effects quite challenging since the desired mesh quality close to the boundaries and within the narrow seal cavities is not always achievable. In case of the above cited studies the heat transfer across the solid boundaries were neglected and except in case of [8] where seal clearances were numerically resolved in the other models the same clearances were modeled by using a resistance parameter or were not modeled at all, in which case the effect of the leakage flow was neglected.

Although deforming meshing seems to be ineludible in the study of Brancher et al. [3] the effect of the rotating rolling piston on the suction and discharge losses was estimated by steady 3D CFD solutions at different crank shaft angles. The predicted effective flow area and effective force area coefficients were implemented into a lumped parameter model. As a result significant improvement in the performance estimation were confirmed by experimental data.

Based on former experiences our preliminary target was to set up a representative CFD model for the newly designed rotary compressor shown in Fig. 1(b) [2] which allows us to investigate the internal flow characteristics in order to understand the driving fluid dynamic phenomena. Assuming that the flow is mainly two-dimensional within the cylinder and the flow becomes significantly three-dimensional just close to the cylinder-outlet transition region, 2D models were also created where the outlet transition was modeled by a varied porosity layer and the results were compared to the $3 \mathrm{D}$ data to justify the validity of the lower dimension model.

\section{Numerical model}

In order to characterize the compressor performance before assembling the complete inverse engine system [2] preliminary experimental tests were planned where the loading of the compressor would be imitated by a simple throttling valve. To numerically resemble this scenario the throttling valve was modeled by a porous layer where the momentum equation has been modified by implementing the Darcy-Forchheimer type source term (Eq. (1)) [9] taking into account only the viscous resistance part (Eq. (2)) for the preliminary computations. For more accurate predictions the permeability and the inertial resistance factor has to be adjusted based on the measured data.

$$
\begin{gathered}
S_{i}=-\left(\frac{\mu}{\alpha} v_{i}+C_{2} \frac{1}{2} \rho\left|v_{i}\right| v_{i}\right) \\
\Delta p=\frac{\mu}{\alpha} v_{i} \Delta n
\end{gathered}
$$

The discharge valve was not modeled since in this case no back-flow from the discharge port was expected as the pressure ratio and the volume of the cavity between the throttling valve and cylinder outlet are relatively small.

Because of meshing considerations there is no direct contact between the different parts at the sealings as it can be seen in Fig. 4(a). The deforming grid provides a connected domain of constant area so no parts of the flow domain are isolated from the rest. The sealings are modeled by a one cell high layer perpendicular to the cross direction (Fig. 4(a)). The flow is restricted by a porous domain defined in a narrow area limited to couple of cells within a given radius around the theoretical contact point of the sealings. Here the porous resistance was also defined only by Eq. (2). At this point the aim was to keep the leakage as small as possible and the value of $1 / \alpha$ in Eq. (2) was the allowed maximum by the solver.

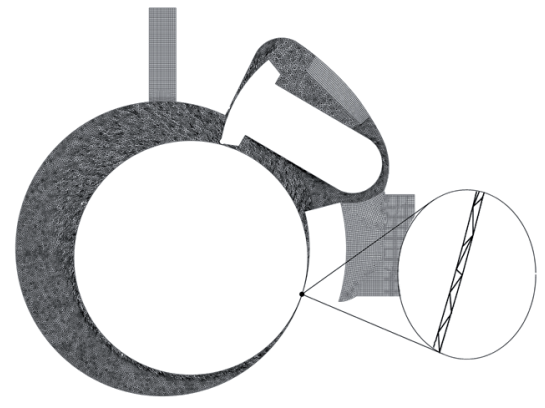

(a)

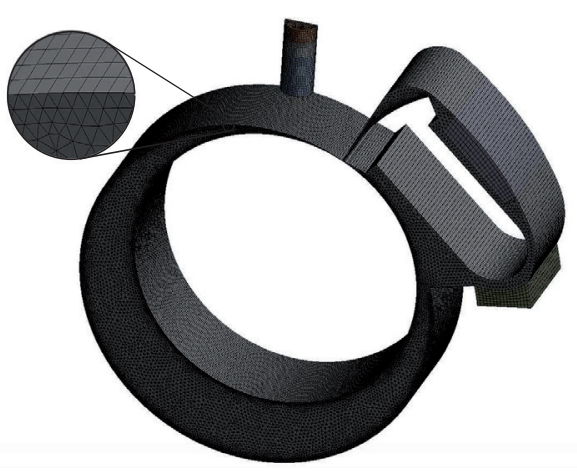

(b)

Fig. 4 2D and sealing gap mesh (a) and 3D wedge mesh (b)

The initial mesh was created using ANSYS Workbench but during the simulation the mesh was controlled by Fluent's dynamic mesh models [9]. The mesh holds only triangle elements within the regions affected by the motion of the moving elements. For the 3D simulations the triangular elements were extruded in the axial direction forming wedge elements 
(Fig. 4(b)) which allows using the 2.5D remeshing approach. In the $2.5 \mathrm{D}$ model the triangular surface mesh is modified only on one side, and the changes are then extruded to the opposite side. Because of the large relative motion of the boundaries the deforming mesh was controlled both by smoothing and remeshing algorithms. For smoothing the Spring/Laplace-based method was used. As the distortion of the cells increases by the large scale movements ANSYS Fluent agglomerates cells that violate the initially defined skewness or size criteria and locally re-meshes the agglomerated cells or faces. If the new cells or faces satisfy the skewness criterion, the mesh is locally updated with the new cells with the solution interpolated from the old cells. Otherwise, the new cells are discarded and the old cells are retained [9]. In the 2D models all the cells are directly connected meanwhile in the 3D model the outlet pipe is connected across a non-conformal mesh interface to the cylinder.

To model turbulent quantities, realizable $\mathrm{k}-\varepsilon$ turbulence model was used, which was proven to be robust and reliable in similar cases $[5,8,10]$. Both at the inlet and the outlet the ambient temperature and pressure boundary conditions were implied. For the preliminary computations the walls were considered to be adiabatic. The working fluid is ideal compressible air.

\subsection{Defining equivalent loading for 2D and 3D computations}

The 3D computations proved to be extremely time consuming. The simulation time for a complete revolution for a $3 \mathrm{D}$ case at $50 \mathrm{~Hz}$ rotational speed took approximately 4.4 days on a i $72600 \mathrm{k}$ processor using all 4 parallel cores. The average mesh counted 236500 cells. Since the time steps could not be increased proportionally by decreasing the rotational speed, computational time increased gradually at lower speeds. Meanwhile $2 \mathrm{D}$ cases at the same rotational speed the computation for one revolution completed within 9 hours on the same architecture. For 2D cases the mesh counted around 27000 cells. The simulation is considered to be periodical after two revolutions. If the effect of the side walls is neglected, it can be assumed that the flow within the compressor is mainly two dimensional except within the close region of the cylinder-outlet joint. Therefore it became obvious that if the 3D effect of the cylinder-outlet transition can be mimicked in 2D and the method with which the the equivalent throttling for $3 \mathrm{D}$ and $2 \mathrm{D}$ cases can be defined then the 2D and 3D cases become comparable. Therefore adequate solution for the most of the flowfield can be achieved with using just 2D simulations with tolerable amount of computational time.

Since the throttling is defined by Eq. (2) a formula for $1 / \alpha$ has to be defined with which its value can be converted from $3 \mathrm{D}$ to $2 \mathrm{D}$ while keeping the loading at the same level. Based on the guidelines in [9] $1 / \alpha$ can be calculated if $\Delta p$ and the ratio of the outlet cross-section areas are known. The 2D simulation is representative for the case when the outlet is extruded to the

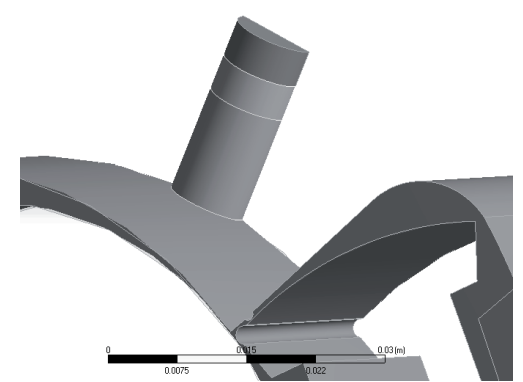

(a)

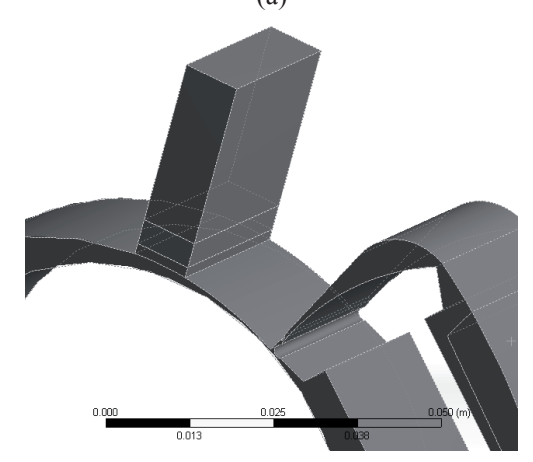

(b)

Fig. 5 Comparing the original 3D model (a) with the model resembled by the $2 \mathrm{D}$ computation (b)

axial direction forming a rectangular exit section which is as wide as the cylinder itself (Fig 5 (b)).

Within one revolution same amount of fluid passes across the outlet in both cases assuming that the leakage flow across the sealing is negligible. Considering Eq. 2 the equivalent value of $1 / \alpha$ can be calculated as follows:

$$
\frac{1 / \alpha_{3 D}}{1 / \alpha_{2 D}}=\frac{1 / \alpha_{c y l}}{1 / \alpha_{\text {rect }}}=\frac{A_{c y l}}{A_{\text {rect }}}=\frac{d \pi}{4 \omega}
$$

If the shorter edge of the rectangular cross section is equal to the diameter of the cylindrical cross section.

\subsection{Modeling the effect of 3D cylinder-outlet transition in 2D}

Besides defining the equivalent throttling, the effect of the sudden area change between the cylinder and the discharge pipe has to be simulated in the $2 \mathrm{D}$ model as well. Since the compression process goes on till the piston reaches the edge of the discharge port, this edge has to be at the same angular position in both $2 \mathrm{D}$ and $3 \mathrm{D}$ cases and also the width of the discharge port in 2D case should be the same as the diameter of the discharge port in the $3 \mathrm{D}$ case. This means that in 2D case the resulted losses are expected to be much less at the intersection of the cylinder and the outlet pipe since the cross-section of the outlet will be much larger than in $3 \mathrm{D}$ (Fig. 5). Considering that the dynamic head is $1 / 2 \rho v^{2}$ perpendicular to an infinitesimal $d A_{k}$ surface element (Fig. 6) and using the inertial part form Eq. (1) a porous layer can be defined for the 2D simulation to establish the following criteria:

$$
\frac{1}{2} \rho v_{r_{\text {circ }}}^{2}=C_{2} \frac{1}{2} \rho\left|v_{r_{\text {rect }}}\right| v_{r_{\text {rect }}} \Delta n
$$




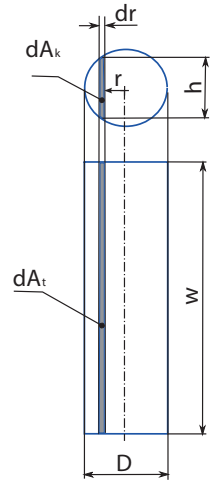

Fig. 6 The relation between the 3D and 2D outlet layouts

Using the former considerations (applying the simple continuity theorem) a distribution of the inertial resistance factor $\left(C_{2}\right)$ in the radial $(r)$ direction of the outlet joint can be derived as follows:

$$
C_{2}(r)=\left(\frac{\omega}{h(r) C_{c}}\right)^{2} \frac{1}{\Delta n}
$$

where $C_{c}$ is the contraction coefficient to simulate the decreased cross section at the vena contracta. The value for $C_{c}$ was chosen based on [11] taking the lowest possible value which is in this case is $C_{c}=0.6$. The calculated distribution of the inertial resistance factor is shown in Fig. 7. The theory was tested on a simplified geometry representative for the outlet section (Fig. 8) which includes the increased resistance porous zone for throttling and also the cylinder-outlet transition model in the 2D case. For the simulations constant mass flow boundary condition was applied at the inlet and at the outlet constant pressure was described. Both for the inlet flow and the outlet back-flow 5\% turbulence intensity (TI) was specified with length scale equal to the tenth of the inlet hydraulic diameter. The results are summarized on Table 1, where $\Delta p_{\text {throttle }}$ is the pressure drop across the porous zone representing the throttling, $\Delta p_{o p}$ is the pressure drop between the point where the cross section suddenly decreases and the outlet boundary and the mass flow rates are given releative to the highest mass flow rate which was simulated:

Table 1 Comparison between the estimated pressure drops calculated with the simplified 2D and 3D models

\begin{tabular}{lccc}
\hline & $\dot{m} / \dot{m}_{\text {III. }}$ & $\Delta \rho_{\text {throttle } 2 D} / \Delta \rho_{\text {throttle3D }}$ & $\Delta \rho_{\text {pop } 2 D} / \Delta \rho_{\text {pop } 3 D}$ \\
\hline I. & 0.07 & 0.93 & 0.97 \\
II. & 0.71 & 0.90 & 1.05 \\
III. & 1.00 & 0.88 & 1.03 \\
\hline
\end{tabular}

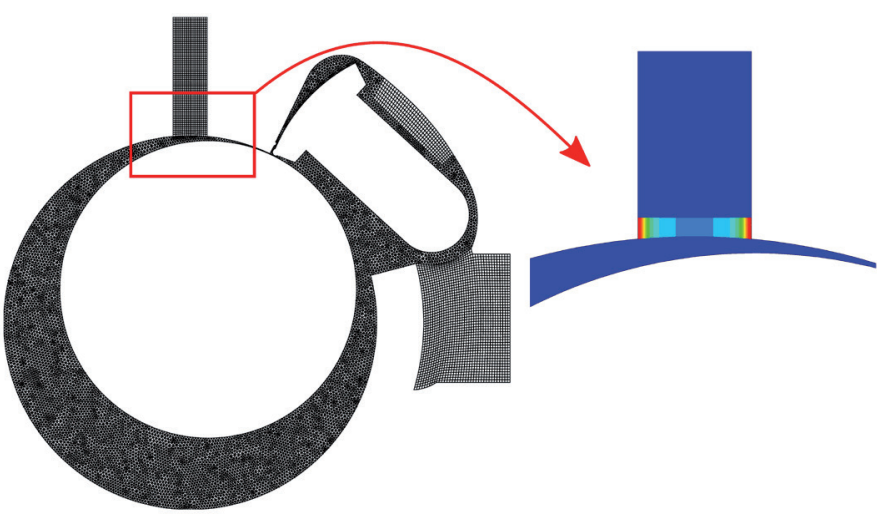

Fig. 7 Distribution of $C 2$ defined by Eq. (5) at the intersection of the cylinder and the outlet joint in the $2 \mathrm{D}$ case

The results suggest that the total pressure drop is slightly overestimated by the $2 \mathrm{D}$ model. It is also visible in Fig. 8 (c) that the porous zone mimicking the transition between the different cross section parallelises the incoming flow and does not allow to form separated zones at the narrow edge between the two sections. The simulations were repeated at different inlet TI levels. The highest difference appeared in $2 \mathrm{D}$ case where the predicted mass flow slightly increased by $0.02 \%$ when the inlet TI was changed from $10 \%$ to $2.5 \%$. Therefore the effect of the inlet TI can be considered negligible within a reasonable range.

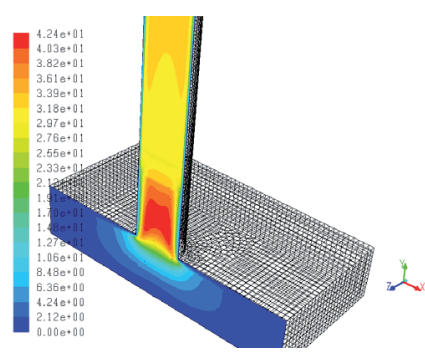

(a) Numerical domain of the 3D model

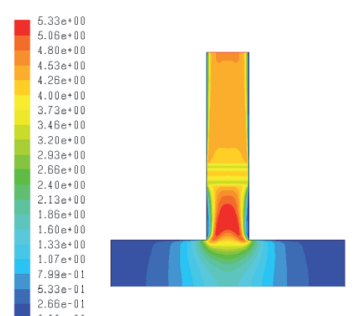

(c) 2D model without simulating the cylinder-outlet joint transition
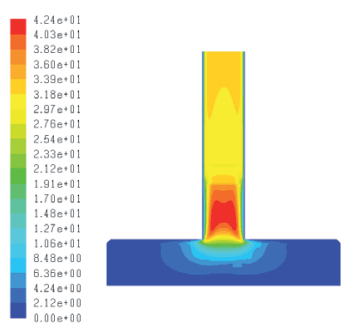

(b) 3D model symmetry surface

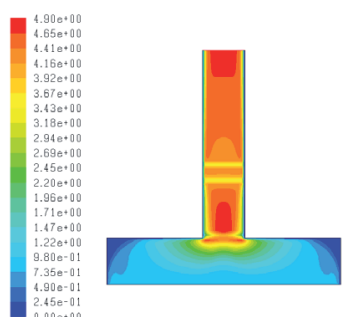

(d) 2D model with simulating the cylinder-outlet joint transition
Fig. 8 Velocity distribution within the simplified exit model, exit model, $v[\mathrm{~m} / \mathrm{s}]$ 


\section{Results}

Figures 9 and 10 show the variation of pressure within the cylinder taken at the inlet of the porous zone representative for the throttling at two different loadings. The pressure increases up to a certain point and reaches its maximum before the piston arrives to the outlet joint. As the compressed air leaves the cylinder faster than compressed volume decreases (Fig. 3), the pressure starts to decrease and reaches the level of the inlet pressure when the piston reaches the outlet joint at around $330^{\circ}$ of crankshaft angle. Unlike in case of the simplified model here the total pressure drop seems to be slightly underestimated by the $2 \mathrm{D}$ compressor model. The corresponding actual mass flow rates are presented in Figs. 11 and 12 where dimensionless rotational speed and mass flow is defined as:
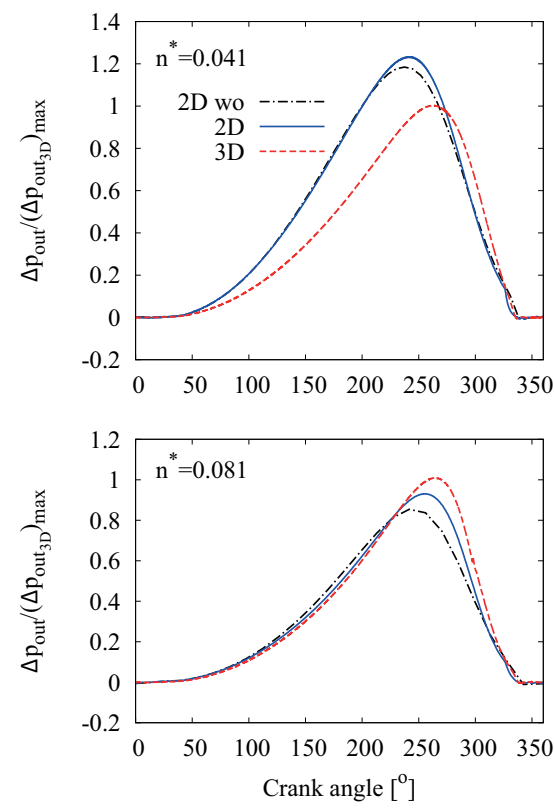

$$
\begin{gathered}
n^{*}=\frac{N_{e}}{\sqrt{R T_{i n}}} \\
m^{*}=\frac{\dot{m} \sqrt{R T_{i n}}}{e^{2} \rho_{i n}}
\end{gathered}
$$

The results with the modified outlet show good agreement with the simulation in most of the cases, and the results were noticeably improved when the cylinder-outlet transition model was added to the simulation. However, a slightly higher discrepancy can be observed at the lowest rotational speed, which has to be investigated (Fig. 9 and 11).
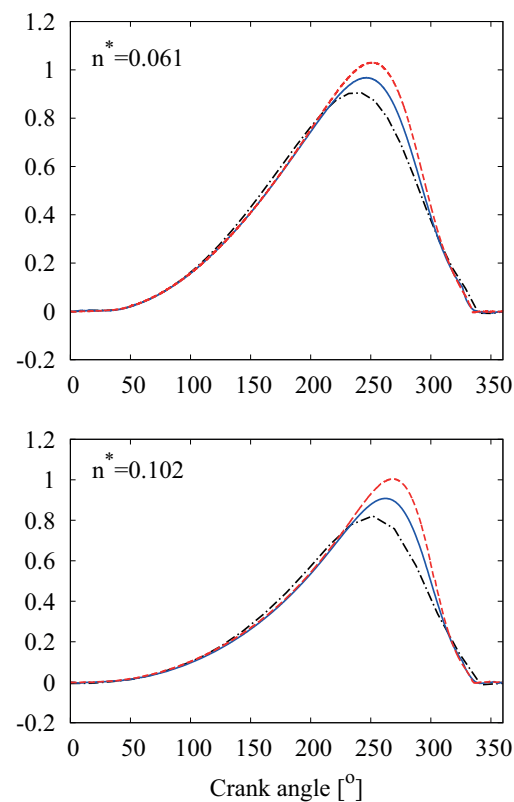

Fig. 9 Pressure upstream from the throttling valve at nominal throttling in function of the crankshaft position. In '2D wo' case cylinder-outlet transition model was not incorporated.
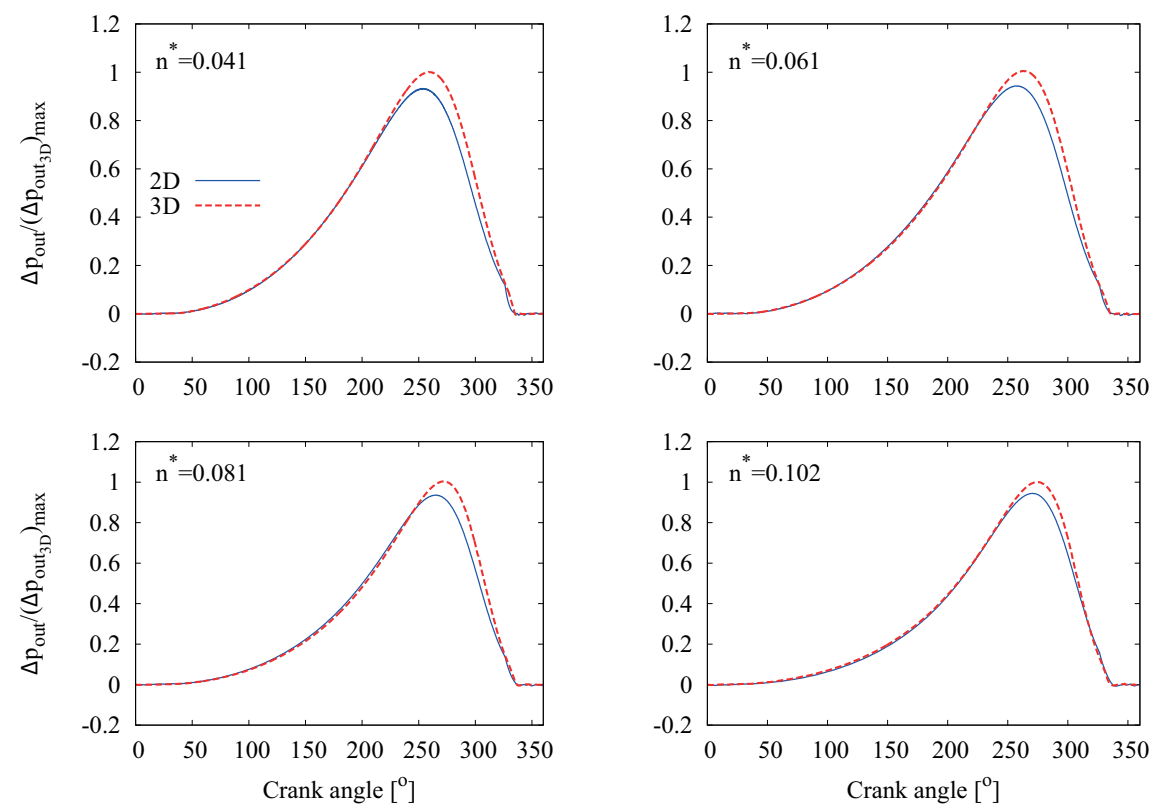

Fig. 10 Pressure upstream from the throttling valve with increased throttling in function of the crankshaft position. 

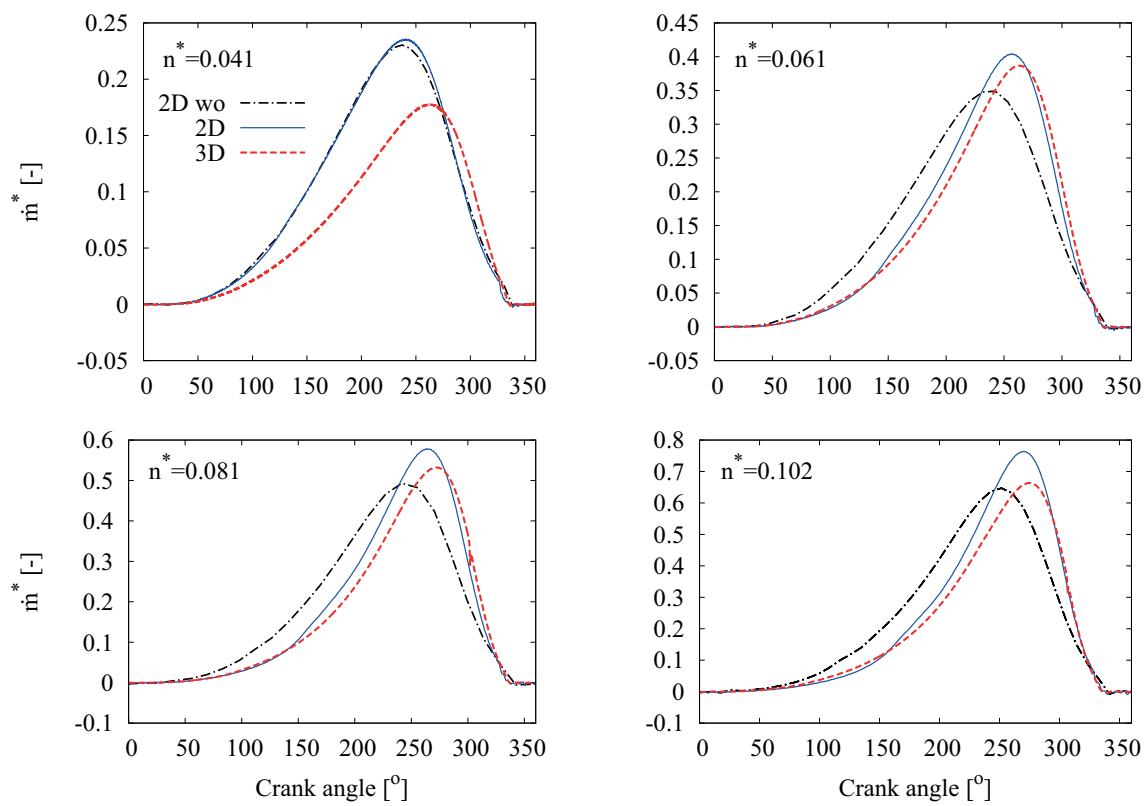

Fig. 11 Outlet non-dimensional flow-rate at different rotational at nominal throttling as a function of the crankshaft position. In '2D wo' case cylinder- outlet transition model was not incorporated.
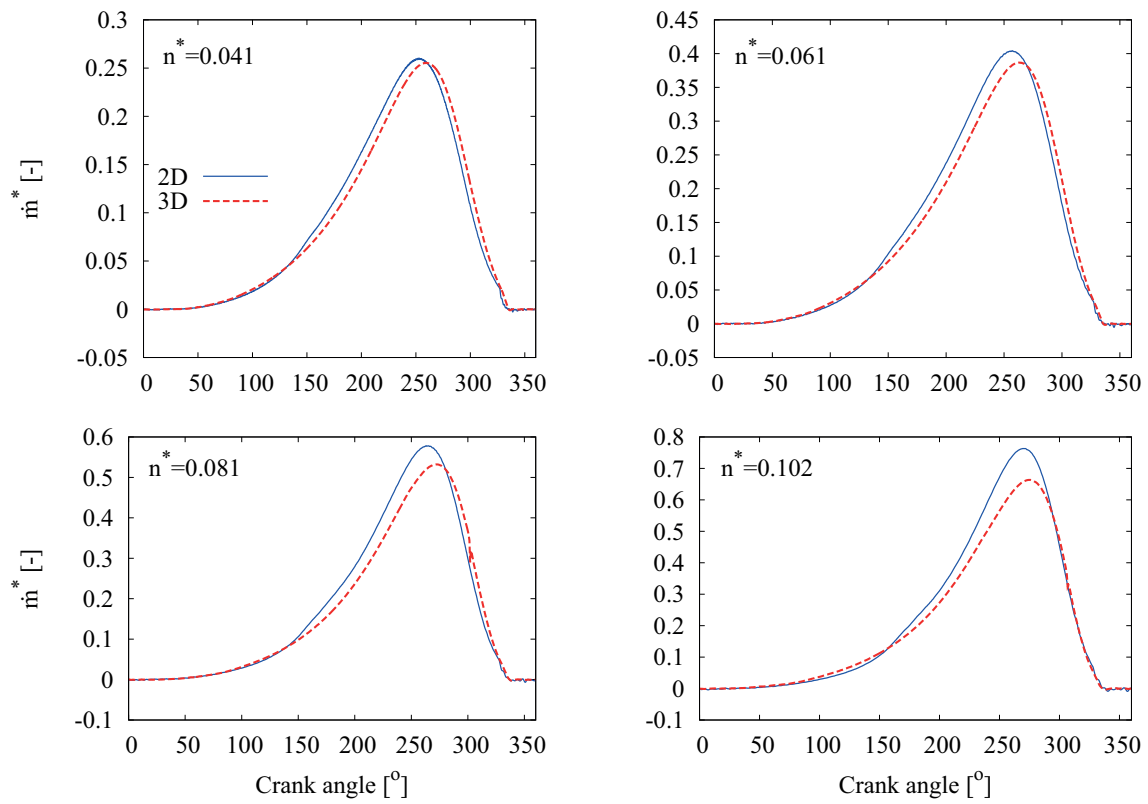

Fig. 12 Outlet non-dimensional flow-rate at different rotational speeds with increased throttling as a function of the crankshaft position.

\section{Conclusions}

A transient CFD model for a newly designed rotary piston compressor architecture was created using ANSYS Fluent. To decrease the simulation cost the model was reduced to $2 \mathrm{D}$. To complete the reduced dimensional model a new method was developed to simulate the 3D effect of the sudden cross section change at the cylinder outlet in 2D. The results of the simulations demonstrates the capability of the new 2D model to estimate the compressor performance in comparison with the 3D computations. However, to actually determine the quality of the model predictions the results have to be compared to experimental data. In possession of the measured data the resistance coefficients used for modeling the leakage flow and the loading need to be calibrated as well to improve the performance estimations.

\section{Nomenclature}

$\Delta n$

$\Delta p$

$\Delta p_{o p}$

$\Delta p_{\text {throttle }}$

$\dot{m}$

A

$\mathrm{C}_{2}$

$C_{c}$

$d$

e

$h$

$N$ streamwise length of the porous zone, $m$ pressure difference, $\mathrm{Pa}$ pressure drop accross the outlet pipe, $P a$ pressure drop accross the throttling valve, $P a$ mass flow rate, $\mathrm{kg} / \mathrm{s}$ surface area, $m^{2}$ intertial resistance factor, $1 / m$ contraction coefficient, outlet joint diameter, $m$ piston eccentricity, $m$ chord length, $m$ rotational speed, $\mathrm{rot} / \mathrm{min}$ non-dimensional rotational speed 


$\begin{array}{ll}p_{i n} & \text { ambient pressure, } P a \\ R & \text { specific gas constant, } \mathrm{J} / \mathrm{kg} / \mathrm{K} \\ r & \text { radial coordinate, } \mathrm{m} \\ S_{i} & \text { source term for the i-th comp. of the } \\ & \text { momentum equation } \\ T_{i n} & \text { ambient temperature, } K \\ v_{i} & \text { i-th comp. of the velocity vector, } \mathrm{m} / \mathrm{s} \\ \omega & \text { width, } m\end{array}$

\section{Greek letters}

$\begin{array}{ll}\alpha & \text { permeability, } 1 / \mathrm{m}^{2} \\ \mu & \text { dynamic viscosity }, \mathrm{kg} / \mathrm{m} / \mathrm{s} \\ \rho & \text { density, } \mathrm{kg} / \mathrm{m}^{3}\end{array}$

\section{Subscripts}

$2 D$

$3 D$

$c y l$

$\max$

rect

\begin{abstract}
two dimensional case three dimensional case cylindrical cross section maximum value rectangular cross section
\end{abstract}

\section{Acknowledgement}

This research was supported by the Research and Technological Development Fund (KMR-12-1-2012-0199) of the Goverment of Hungary.

\section{References}

[1] "Compressors. 2000 ASHRAE Systems and Equipment Handbook." 2000.

[2] Magai, I. http://www.magaimotor.magai.eu. [Accessed: 25th January 2014].

[3] Brancher, R. D., Deschamps, C. J. "Modeling of rolling-piston compressors with special attention to the suction and discharge processes." In: Proceedings of the International Compressor Engineering Conference at Purdue. July 14-17 2014.

[4] Prasad, B. G. "CFD for positive displacement compressors." In: Proceedings of the International Compressor Engineering Conference. number 1689, July 12-15 2004.

[5] Liu, C. H., Geng, W. "Research on suction performance of twocylinder rolling piston type rotary compressors based on CFD simulation." In: Proceedings of the International Compressor Engineering Conference at Purdue. July 12-15 2004.

[6] Liang, S., Xia, S., Kang, X., Zhou, P., Liu, Q., Hu, Y. "Investigation of refrigerant flow simulation and experiment of rolling piston." In: Proceedings of the International Compressor Engineering Conference at Purdue, July 12-15 2010 .

[7] Montenegro, G., Della Torre, A., Fiocco, M., Onorati, A., Benatzky, C., Schlager, G. "Evaluating the performance of a rotary vane expander for small scale organic rankine cycles using CFD tools." In: Proceedings of the 68th Conference of the Italian Thermal Machines Engineering Association. Bologna, Italy, September 11-13 2013.

[8] Ding, H., Gao, H. "3-D transient CFD model for rolling piston compressor with dynamic reed valve." In: Proceedings of the International Compressor Engineering Conference at Purdue, July 14-17 2014.

[9] ANSYS Fluent documentation. v14.5, http://www.ansys.com/, [Accessed: 12th December 2012].

[10] Gao, H., Jiang, Y. "Numerical simulation of unsteady flow in a scroll compressor." In: Proceedings of the International Compressor Engineering Conference at Purdue. July 14-17 2014.

[11] Lajos, T. "Az áramlástan alapjai." (Fundamentals of Fluid Mechanics.) Dr. Lajos Tamás, Budapest, 2008. (in Hungarian) 